\title{
Interannual Change Detection of Mediterranean Seagrasses Using RapidEye Image Time Series
}

\author{
${\text { Dimosthenis } \text { Traganos }^{1 *} \text { and Peter Reinartz }}^{2}$ \\ ${ }^{1}$ Department of Photogrammetry and Image Analysis, German Aerospace Center Deutsches Zentrum für Luft-und \\ Raumfahrt, Remote Sensing Technology Institute, Berlin, Germany, ${ }^{2}$ Department of Photogrammetry and Image Analysis, \\ German Aerospace Center Deutsches Zentrum für Luft-und Raumfahrt, Remote Sensing Technology Institute, Wessling, \\ Germany
}

\section{OPEN ACCESS}

Edited by:

Janne Alahuhta,

University of Oulu, Finland

Reviewed by:

Franziska Schrodt,

University of Nottingham,

United Kingdom

David John Wilcox,

Virginia Institute of Marine Science,

United States

*Correspondence:

Dimosthenis Traganos dimosthenis.traganos@dlr.de

Specialty section:

This article was submitted to Functional Plant Ecology,

a section of the journal

Frontiers in Plant Science

Received: 25 August 2017 Accepted: 17 January 2018 Published: 06 February 2018

Citation:

Traganos D and Reinartz P (2018) Interannual Change Detection of Mediterranean Seagrasses Using

RapidEye Image Time Series.

Front. Plant Sci. 9:96

doi: 10.3389/fpls.2018.00096
Recent research studies have highlighted the decrease in the coverage of Mediterranean seagrasses due to mainly anthropogenic activities. The lack of data on the distribution of these significant aquatic plants complicates the quantification of their decreasing tendency. While Mediterranean seagrasses are declining, satellite remote sensing technology is growing at an unprecedented pace, resulting in a wealth of spaceborne image time series. Here, we exploit recent advances in high spatial resolution sensors and machine learning to study Mediterranean seagrasses. We process a multispectral RapidEye time series between 2011 and 2016 to detect interannual seagrass dynamics in 888 submerged hectares of the Thermaikos Gulf, NW Aegean Sea, Greece (eastern Mediterranean Sea). We assess the extent change of two Mediterranean seagrass species, the dominant Posidonia oceanica and Cymodocea nodosa, following atmospheric and analytical water column correction, as well as machine learning classification, using Random Forests, of the RapidEye time series. Prior corrections are necessary to untangle the initially weak signal of the submerged seagrass habitats from satellite imagery. The central results of this study show that $P$. oceanica seagrass area has declined by $4.1 \%$, with a trend of -11.2 ha/yr, while $C$. nodosa seagrass area has increased by $17.7 \%$ with a trend of $+18 \mathrm{ha} / \mathrm{yr}$ throughout the 5 -year study period. Trends of change in spatial distribution of seagrasses in the Thermaikos Gulf site are in line with reported trends in the Mediterranean. Our presented methodology could be a time- and cost-effective method toward the quantitative ecological assessment of seagrass dynamics elsewhere in the future. From small meadows to whole coastlines, knowledge of aquatic plant dynamics could resolve decline or growth trends and accurately highlight key units for future restoration, management, and conservation.

\footnotetext{
Keywords: Posidonia oceanica, Cymodocea nodosa, Mediterranean seagrasses, Thermaikos Gulf, RapidEye, time series, change detection, Random Forests
}

\section{INTRODUCTION}

Seagrasses are one of the most vital constituents of the Mediterranean coastal environment. Spanning a depth range between 0 and $45 \mathrm{~m}$ where there is enough light availability for their growth, these marine flowering plants play a major role in the great Mediterranean biodiversity of $18 \%$ of all known marine species (Coll et al., 2010). In addition to enhancing biodiversity, 
Mediterranean seagrasses contribute to a plethora of valuable ecosystem services (Costanza et al., 1997; Vassallo et al., 2013; Campagne et al., 2015) including nursery grounds (Giannoulaki et al., 2013), coastal erosion buffering (Pergent et al., 2012), bio-indicator (Mtwana Nordlund et al., 2016), and carbon sequestration (Fourqurean et al., 2012). Regarding the latter ecosystem service, Mediterranean seagrass meadows store the largest pools of the remineralization of organic carbon; nearly three times greater mean living biomass is present in the Mediterranean seagrasses than the global mean of nine seagrass bioregions (Fourqurean et al., 2012).

Despite their ecological value and being a conservation priority of national and international legislations, Mediterranean seagrasses have faced regression between 10 and 38\% during the last 50 years (Tomas et al., 2005; Marbà et al., 2014; Telesca et al., 2015). This regression has been mainly attributed to anthropogenic activities including trawling, coastal artificialization, anchoring of heavy ships, dredging, and climate change (Leriche et al., 2006; Waycott et al., 2009; Jordà et al., 2012; Bonacorsi et al., 2013). The slow growth of $3-4 \mathrm{~cm} / \mathrm{yr}$ of $P$. oceanica seagrass along with the sparsity of data on the distribution of Mediterranean seagrass habitats, mainly in the southern and eastern Mediterranean (Telesca et al., 2015), hamper any effort for their effective conservation management. The question then arises: how can we conserve something which grows slow, declines fast, and we have limited information on its spatial distribution?

The answer to the above question may lie in Earth observation. In contrast and somewhat parallel to the decreasing trend in coverage of Mediterranean seagrass meadows, satellite remote sensing technology has grown at an unprecedented pace, mainly since the end of the 1990s (Dekker et al., 2006). Advances in Earth observation have resulted from single sensors (e.g., Landsat 7 and 8, SPOT 4-7, QuickBird 2, WorldView 1-4) to constellations of satellites (e.g., Sentinel-2, Planet's RapidEye and Doves). This swarm of satellites images the Earth's surface with medium to high spatial (0.31-30 m), temporal (1-16 days), spectral, and radiometric resolution.

Applied to the coastal environment, spaceborne image archives allow multi-temporal analysis and change detection of submerged ecosystems which could in turn permit identification of possible degradation rates and boost conservation efforts of these problematic areas (Purkis and Roelfsema, 2015). Researchers have previously employed spaceborne time series to map seasonal to decadal change detection of seagrasses (Dekker et al., 2005; Knudby et al., 2010; Lyons et al., 2012; Pu et al., 2014; Roelfsema et al., 2014; Hossain et al., 2015). The time-series analysis of seagrass communities is as accurate as the classification algorithms in use (Palandro et al., 2003). More recently, machine learning algorithms (e.g., Random Forests, Support Vector Machines, k-nearest neighbors) have overruled simpler classification algorithms in the remote sensing literature (Gislason et al., 2006; Mountrakis et al., 2011). However, machine learning has been sparsely implemented in the quantitative assessment of coastal environments (Zhang, 2015).
In this study, our main aim is to combine recent advances in high spatial resolution sensors and machine learning algorithms to study the interannual dynamics of Mediterranean seagrasses by processing and analyzing a multispectral RapidEye time series in the Thermaikos Gulf, NW Aegean Sea (Greece) between 2011 and 2016. Featuring a great water transparency, small depth slope and thriving in two seagrass species, Posidonia oceanica and Cymodocea nodosa (Traganos and Reinartz, 2017; Traganos et al., 2017), the southeastern shelf Thermaikos Gulf comprises a suitable natural laboratory to apply our spaceborne change detection analysis. The spatio-temporal dynamics and sources of observed variations of Mediterranean seagrass habitats, namely the intertidal Zostera noltii and C. nodosa species, have been assessed before through spaceborne and airborne time series (Barillé et al., 2010; Garrido et al., 2013). The ecological status of the dominant and endemic in the Mediterranean, $P$. oceanica, however, has not been assessed yet via change detection analysis. RapidEye constellation of five satellites was the first to provide high spatial resolution data with a daily revisit time over the same area ${ }^{1}$. There have been few applications of RapidEye data in aquatic habitat mapping (Roessler et al., 2012; Giardino et al., 2015; Fritz et al., 2017). In general, temporally separated satellite image sequences over coastal areas acquired under different conditions (e.g., atmospheric, water column composition) can impede the change detection mapping of submerged habitats like seagrasses (Purkis and Roelfsema, 2015).

\section{MATERIALS AND METHODS}

\section{Study Site}

The study site is a submerged area of 888 hectares in the eastern Thermaikos Gulf, NW Aegean Sea, Greece (eastern Mediterranean Sea; Figure 1). The climate, oceanography, and hydrography of its water have been comprehensively described elsewhere (Poulos et al., 2000; Traganos and Reinartz, 2017). Satellite-derived mapping has revealed that the Thermaikos Gulf contains extensive beds of varying density of two seagrass species, P. oceanica and C. nodosa, between 1.4 and $16.5 \mathrm{~m}$ of depth (Traganos and Reinartz, 2017; Traganos et al., 2017).

The coastal system of the eastern Thermaikos Gulf administratively belongs to the Municipality of Nea Propontida. With a population of $36,500^{2}$, Nea Propontida hosts numerous socioeconomic activities including fishing, aquaculture, tourism, agriculture, industry, and trade directly or indirectly influence the marine environment. Furthermore, the administrative region of Central Macedonia, which contains Nea Propontida, features a total fishing catch of $11,869 \mathrm{t}(18.5 \%$ of the total Greek fishing (atch) ${ }^{3}$. Last but not least, $19.3 \%$ of the total citizens of the municipality are employed in the primary sector, while 66 factories and 91 hotels are running in the coastal region $^{2}$.

\footnotetext{
${ }^{1}$ https://www.planet.com/products/satellite-imagery/files/160625-RapidEye $\% 20$ Image-Product-Specifications.pdf.

${ }^{2}$ National Statistics Service of Greece, 2011.

${ }^{3}$ National Statistics Service of Greece, 2015.
} 


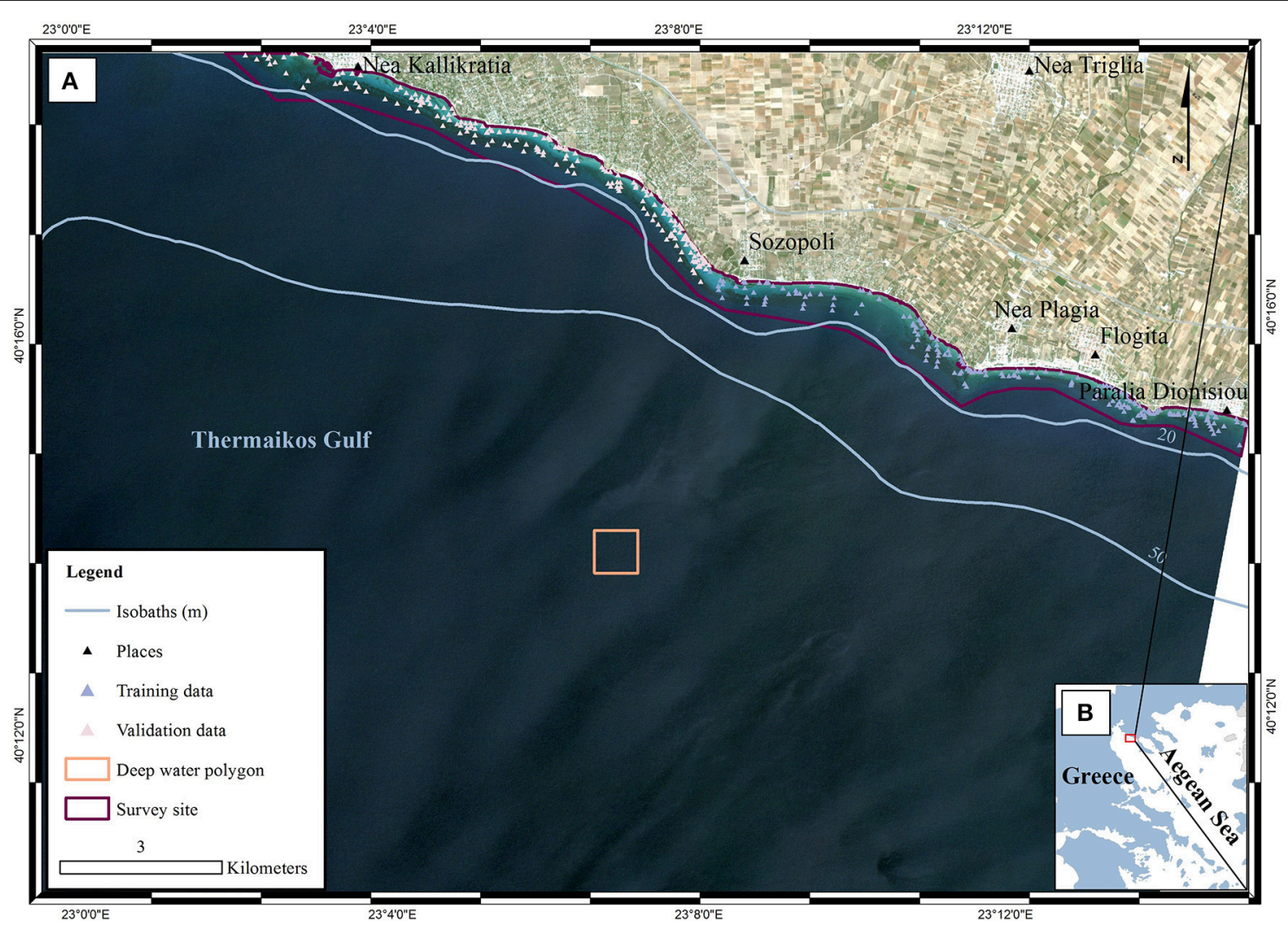

FIGURE 1 | Location of survey site within (A) Thermaikos Gulf, (B) Aegean Sea, Greece. The displayed RapidEye imagery is a non-atmospherically corrected, true color (band 1 as blue, band 2 as green, band 3 as red) composite in UTM (zone 34) system/WGS84 projection. The imagery was acquired on 22/06/2016 (RE16 in text). The red polygon in (B) depicts the location of (A) within the Thermaikos Gulf. The deep water polygon represents a $\sim 160 \times 160$ pixel window implemented in the water column correction of the image time series as it represents an area with very little water leaving radiance values in all three bands.

\section{Satellite Data}

Planet's RapidEye constellation consists of five multispectral (five bands between 440 and $850 \mathrm{~nm}$ ) satellites which collect highspatial (5-m orthorectified pixel size) and temporal (daily offnadir and 5.5 days at nadir) imagery. Although designed to operate for a minimum of seven years, RapidEye satellites have already collected an 8-year image archive. Fourty-seven Level $3 \mathrm{~A}$ image tiles fell within the extent of our study site. These tiles are individual $25 \times 25 \mathrm{~km}$ orthorectified imagery products with applied geometric, radiometric, and sensor corrections ${ }^{1}$. Based on a preliminary visual examination, we selected four from these image tiles (Table 1) which satisfied optimum conditions for remote sensing of optically shallow environment (e.g., cloud, sunglint- and skyglint-free, no or low concentration of water column constituents, same season). The four images comprise a time series which spans the years between 2011 and 2016. For ease, we will refer to the four images with the abbreviation RE (stands for RapidEye) and the two last digits from the year of acquisition; RE11, RE12, RE15, RE16.

\section{Field Data}

The field data collection is described in Traganos and Reinartz (2017). We collected these field data, namely habitat-related
TABLE 1 | Characteristics of the high spatial resolution satellite imagery and respective input parameters for running FLAASH module.

\begin{tabular}{llcll}
$\begin{array}{l}\text { Satellite } \\
\text { imagery }\end{array}$ & $\begin{array}{l}\text { Scene acquisition } \\
\text { date (dd/mm/year) }\end{array}$ & $\begin{array}{c}\text { Scene acquisition } \\
\text { time (local) }\end{array}$ & $\begin{array}{l}\text { Atmospheric } \\
\text { model }\end{array}$ & $\begin{array}{l}\text { Aerosol } \\
\text { model }\end{array}$ \\
\hline RE11 & $13 / 05 / 2011$ & $13: 23$ & $S^{1} S^{1}$ & Maritime \\
RE12 & $24 / 09 / 2012$ & $13: 16$ & MLS $^{2}$ & Rural \\
RE15 & $18 / 09 / 2015$ & $12: 57$ & MLS & Maritime \\
RE16 & $22 / 06 / 2016$ & $12: 53$ & MLS & Maritime
\end{tabular}

RE, RapidEye, $5 \times 5$ m pixel, blue, green, red, red edge, nir. ${ }^{1}$ Sub-Arctic Summer. ${ }^{2}$ Mid-Latitude Summer.

points with associated coordinates and bathymetry data, during a boat-based survey between 10 and 13 July 2016. Furthermore, we added more data points following interpretation of the high resolution RapidEye imagery. We selected data points that have indicated the same habitat within the 5-year span of our time series analysis. Four-hundred data points (Figure 1) were used for both training and validation of the machine learning classifier implemented here. In the bathymetry estimation step, we employed the image chronologically closest to the field data collection, RE16, to develop a pixel-based bathymetry map for subsequent use in the water column correction step. 


\section{Methodology}

To derive quantitative information from coastal image time series using remote sensing, the analyst has to address the interference of the atmospheric, air-water interface, and water column by applying the same processing protocol on all satellite images which comprise the image time series. Figures 2, 3 show a schematic and visual representation of the processed protocol herein, respectively, until the classification step. The pre-classification steps which we followed in the present study included: (1) atmospheric correction to derive at-water surface reflectances without atmospheric interference (Figure 4B), (2) bathymetry estimation for use in the water column correction step (Figure 4C), and (3) water column correction to derive bottom reflectances without water column interference (Figure 4D). The classification step concerned the use of Random Forests (RF), an ensemble supervised classification algorithm which has received small attention in the remote sensing of optically shallow environments. The accuracy assessment of the RF-derived results was performed using the traditional error matrices reporting overall, producer, user, and kappa accuracies (Table 2). Finally, we conducted the interannual change detection of the two
Mediterranean seagrass species, $P$. oceanica and $C$. nodosa, on the basis of area change and related trend throughout the 4 years.

\section{Atmospheric Correction}

The first step of the pre-classification procedure was the atmospheric correction. We implemented the Fast Line-ofsight Atmospheric Analysis of Spectral Hypercubes (FLAASH) algorithm to correct the atmospheric interference on all RE images. The input parameters to run the FLAASH module are described in Table 1. All aerosol models were set as Maritime type except from the RE12 imagery for which experiments using the same type resulted to negative reflectances, therefore, we used the Rural type. The FLAASH module resulted to at-water surface reflectances, $R$, of all $5 \mathrm{RE}$ bands (Figure 4B). The positional accuracy on the initial Level $3 \mathrm{~A}$ RE image tiles was found to be adequate, hence we performed no additional coregistration on the four RE images which is a necessary step otherwise due to the pixel-based approach of the present study. In addition, due to our preliminary visual examination of the Level $3 \mathrm{~A}$ products, no evident sunglint was found in the at-water surface reflectance composites.

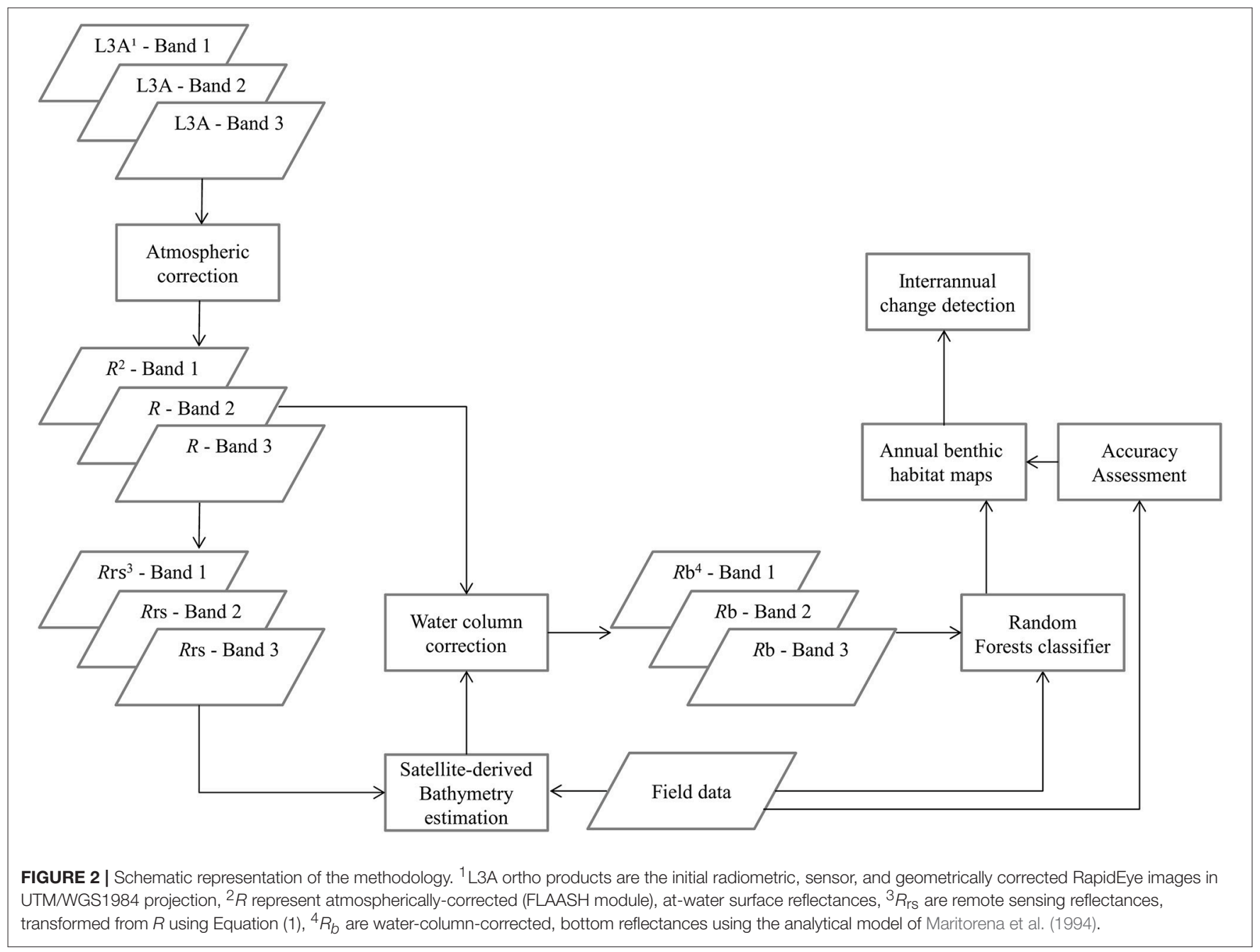




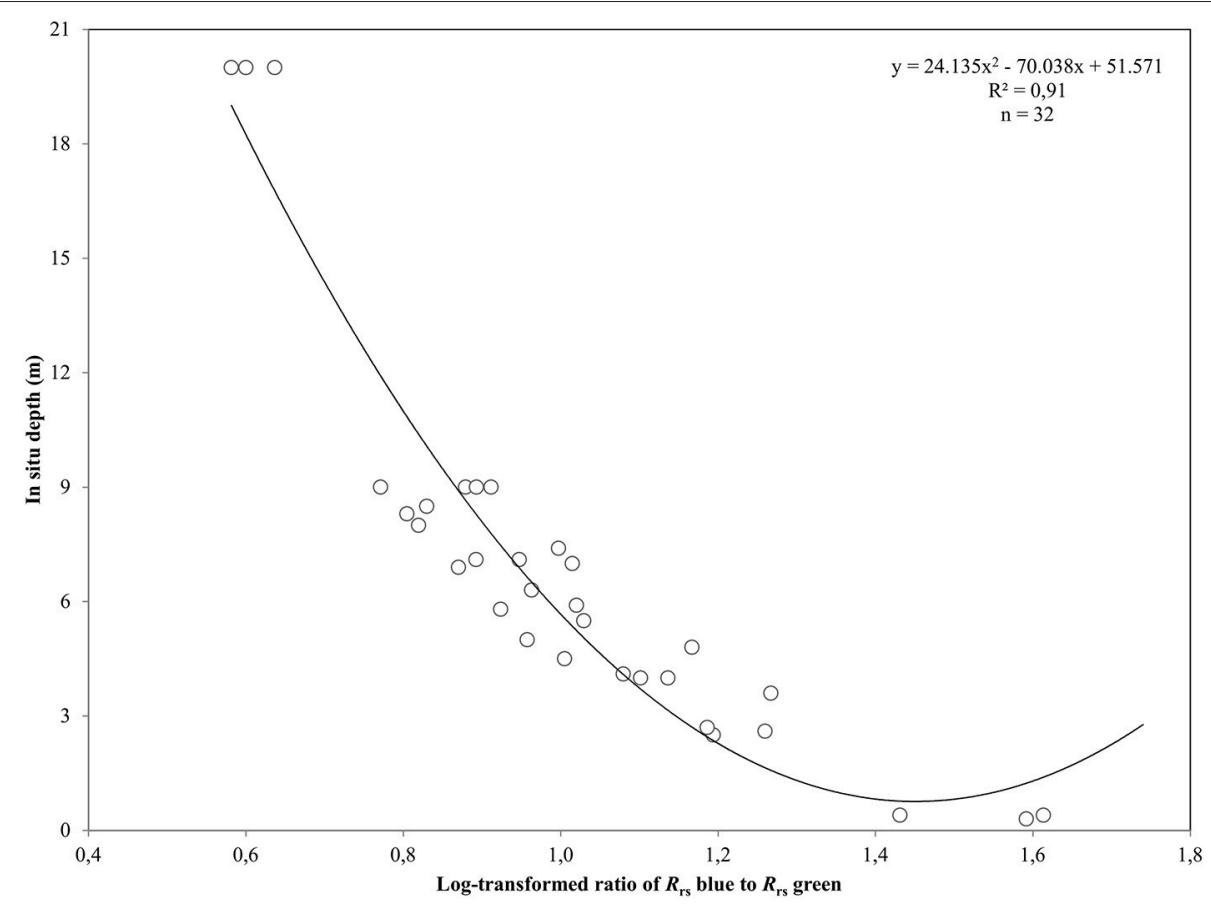

FIGURE 3 | Polynomial regression between the log-transformed ratio of blue and green remote sensing reflectances, $R_{\mathrm{rs}}$, and in situ depth measurements from the Thermaikos survey site. The shown polynomial equation was implemented to estimate the bathymetry map displayed in (C) of Figure 4.

\section{Bathymetry Estimation}

Bathymetry knowledge of a coastal site is crucial to reduce reflectance changes due to water column attenuation and variable depth. Differences between reflectances of coexisting submerged habitats can hinder their detection through remote sensing. As a result of the shading which occur within the canopy, $P$. oceanica seagrass exhibit lower reflectances than its seaward neighbor, optically deep water (Dekker et al., 2006). Coupled with the high reflectances of a submerged sandy substrate, $P$. oceanica would look deeper than the sandy substrate at the same true depth (Traganos and Reinartz, 2017). Remote sensing researchers have developed band ratios to tackle the aforementioned issues and to measure bathymetry (Lyzenga, 1978; Dierssen et al., 2003; Stumpf et al., 2003). The basic assumption of band ratios is that the reflectance ratio in these bands remains constant irrespectively of the submerged environment.

To further eliminate interference at air-water interface, we chose to retrieve pixel-based bathymetry from the remote sensing reflectance, $R_{\mathrm{rs}}$, which is also less sensitive to water column properties (Mobley, 1994). We derived $R_{\mathrm{rs}}$ from at-water surface reflectances, $R$, using

$$
R_{r s}=\frac{t R}{Q}
$$

where $t$ is the transmittance of $E_{\mathrm{d}}$, spectral downwelling plane irradiance, and $L_{\mathrm{u}}$, spectral upwelling radiance, through the airwater interface and was calculated as 0.54 by Mobley (1994). Q factor is the ratio of $E_{\mathrm{u}}$, spectral upwelling plane irradiance, and $L_{\mathrm{u}}$ just beneath the water surface and depends on the type and depth of the bottom and the wavelength. We chose the $\pi$ value for $Q$ factor for the calculations of $R_{\mathrm{rs}}$, which is the theoretical value for Lambertian surfaces (Dierssen et al., 2003). We mapped the bathymetry of our survey site using the log-ratio of $R_{\mathrm{rs}}$ blue to $R_{\mathrm{rs}}$ green at 475 and $555 \mathrm{~nm}$ from RE16, respectively. We used RE16 because it is closer chronologically to our in situ data acquisition of July 2016. The first two RapidEye bands are attenuated less in the water column than the ones in the red, red edge and NIR. Thus, they comprise the ideal contestants to develop a second-order polynomial after plotting their ratio against in situ estimated bathymetry, $Z$

$$
\begin{array}{r}
Z=24.135 x^{2}-70.038 x+51.571 \\
x=\ln \left(\frac{R_{\mathrm{rs}}(475)}{R_{\mathrm{rs}}(555)}\right)
\end{array}
$$

which explained $>91 \%$ of the variation $(p<0.001)$ in estimated bathymetry in 32 points (Figure 3) which spanned the whole depth range of habitat presence in our survey site. The sitespecific algorithm of (2) was subsequently employed to create a pixel-based bathymetry map (Figure 4C). This bathymetry was further smoothed with a $5 \times 5$ low pass filter to reduce local variation and unwanted noise which would impede water column correction and possibly decrease classification accuracy. Based on the satellite-derived bathymetry and the findings of Traganos and Reinartz (2017), we applied an optically deep water mask utilizing the depth limit of $16.5 \mathrm{~m}$ to enhance submerged features in the classification step. 
TABLE 2 | Error matrices of the four water-column corrected bottom reflectance images.

\begin{tabular}{|c|c|c|c|c|c|c|}
\hline Classes & $\begin{array}{c}\text { Cymodocea } \\
\text { nodosa }\end{array}$ & $\begin{array}{c}\text { Posidonia } \\
\text { oceanica }\end{array}$ & $\begin{array}{l}\text { Rocky } \\
\text { algae }\end{array}$ & Sand & Total & $\begin{array}{c}\text { User } \\
\text { accuracy (\%) }\end{array}$ \\
\hline $\begin{array}{l}\text { Cymodocea } \\
\text { nodosa }\end{array}$ & 16 & 1 & 2 & 2 & 21 & 76.2 \\
\hline $\begin{array}{l}\text { Posidonia } \\
\text { oceanica }\end{array}$ & 3 & 46 & 3 & 1 & 53 & 86.8 \\
\hline Rocky algae & 2 & 3 & 38 & 0 & 43 & 88.4 \\
\hline Sand & 29 & 0 & 7 & 47 & 83 & 56.6 \\
\hline Total & 50 & 50 & 50 & 50 & 200 & \\
\hline $\begin{array}{l}\text { Producer } \\
\text { accuracy }\end{array}$ & 32 & 92 & 76 & 94 & & \\
\hline \multicolumn{7}{|c|}{ 2011-OVERALL ACCURACY: $73.5 \%$} \\
\hline $\begin{array}{l}\text { Cymodocea } \\
\text { nodosa }\end{array}$ & 31 & 4 & 0 & 1 & 36 & 86.1 \\
\hline $\begin{array}{l}\text { Posidonia } \\
\text { oceanica }\end{array}$ & 0 & 45 & 0 & 0 & 45 & 100 \\
\hline Rocky algae & 0 & 0 & 37 & 0 & 37 & 100 \\
\hline Sand & 19 & 1 & 13 & 49 & 82 & 59.8 \\
\hline Total & 50 & 50 & 50 & 50 & 200 & \\
\hline Producer & 62 & 90 & 74 & 98 & & \\
\hline
\end{tabular}

accuracy

\begin{tabular}{|c|c|c|c|c|c|c|}
\hline \multicolumn{7}{|c|}{ 2012-OVERALL ACCURACY: 81\% } \\
\hline $\begin{array}{l}\text { Cymodocea } \\
\text { nodosa }\end{array}$ & 30 & 11 & 0 & 0 & 41 & 73.2 \\
\hline $\begin{array}{l}\text { Posidonia } \\
\text { oceanica }\end{array}$ & 1 & 38 & 1 & 0 & 40 & 95 \\
\hline Rocky algae & 0 & 1 & 40 & 1 & 42 & 95.2 \\
\hline Sand & 19 & 0 & 9 & 49 & 77 & 63.6 \\
\hline Total & 50 & 50 & 50 & 50 & 200 & \\
\hline Producer & 60 & 76 & 80 & 98 & & \\
\hline
\end{tabular}

accuracy

$\begin{array}{lcccccc}\text { 2015-OVERALL ACCURACY: } \mathbf{7 8 . 5 \%} & & & & \\ \begin{array}{l}\text { Cymodocea } \\ \text { nodosa }\end{array} & 23 & 1 & 0 & 1 & 25 & 89.3 \\ \begin{array}{l}\text { Posidonia } \\ \text { oceanica }\end{array} & 6 & 49 & 3 & 0 & 58 & 79.3 \\ \text { Rocky algae } & 0 & 0 & 43 & 0 & 43 & 100 \\ \begin{array}{l}\text { Sand } \\ \text { Total }\end{array} & 21 & 0 & 4 & 49 & 74 & 55 \\ \text { Producer } & 50 & 50 & 50 & 50 & 200 & \\ \text { accuracy } & 46 & 98 & 86 & 98 & & \end{array}$

accuracy

2016-OVERALL Accuracy: $82 \%$

Date of each imagery is provided on the low left of each error matrix before Overall accuracy.

\section{Water Column Correction}

The water column correction step is vital to retrieve bottom reflectances from at-water surface reflectances. Here, we employ the approximate analytical solution of Maritorena et al. (1994) for optically shallow waters.

$$
R(\lambda)=R_{\infty}(\lambda)+\left(R_{\mathrm{b}}(\lambda)-R_{\infty}(\lambda)\right) \exp \left(-2 K_{\mathrm{d}}(\lambda) Z\right)
$$

where $R(\lambda)$ is the atmospherically-corrected at-water surface reflectance composite of Atmospheric Correction (Figure 4B);
$R_{\infty}(\lambda)$ is the reflectance over an infinitely deep water column; $R_{\mathrm{b}}(\lambda)$ is the bottom reflectance (Figure $4 \mathrm{D}$ ); $K_{\mathrm{d}}(\lambda)$ is the operational attenuation coefficient which expresses the attenuation of both upwelling and downwelling stream as these are originating from the seabed and from the water column (Maritorena et al., 1994). Ideally, $R_{\infty}(\lambda)$ and $K_{\mathrm{d}}(\lambda)$ are estimated using in situ optical measurements and radiative transfer simulations. In the absence of these, we used imagebased techniques and existing measurements (Traganos and Reinartz, 2017). For the infinitely deep water column reflectance, $R_{\infty}(\lambda)$, we extracted mean values from the deep water polygon of Figure 1A from the at-water surface reflectance RE16 composite, mean values which composed $R_{\infty}(\lambda)$ for all four images of the RE time series. For the $K_{d}(\lambda)$, we used imagebased calculated values for the water column corrections of all four dates from Traganos and Reinartz (2017) who used Bierwirth et al. (1993) approximations in the same area. Bottom reflectances (Figure 4D) were calculated for every pixel of the first three bands of the atmospherically corrected, at-water surface reflectance composites of all four RE images. We selected RE bands 1, 2, and 3 at 475, 555, and $658 \mathrm{~nm}$ since seagrasses and, generally, underwater habitats cannot be detected by wavelengths past $680 \mathrm{~nm}$ due to the great attenuation of pure water (Kirk, 1994). Last but not least, to save valuable space in the remaining text, we will refer to each quantity which is wavelength-dependent without its wavelength notation except when it is needed i.e., to discriminate between two quantities.

\section{Random Forest Classification}

The machine learning approach of Random Forests (RF) comprises an ensemble supervised classification algorithm that implements multiple self-learning decision trees to handle collinearity and, more significantly, non-linearity between predictor variables. Developed by Breiman (2001), RF are based on the assumption that different independent tree predictors give wrong predictions in different regions. By combining the results of the predictions, RF improve the efficiency of the model. Every decision tree in the implemented RF algorithm here is trained with a bootstrapped sample of the training data and at every split node, a subset of randomly selected features is utilized. The outputs are then combined by a simple majority vote. Generally, $\mathrm{RF}$ are robust against overtraining and noisy data in addition to providing good results with relatively small datasets (Gislason et al., 2006). Three parameters must be set before running the RF classifier: (a) the number of decision trees $(k)$, (b) the number of randomly selected features $\left(n_{\mathrm{r}}\right)$, and $(\mathrm{c})$ the split selection. We selected 100 trees to run all RF experiments as they featured the best results out of a plethora of runs with different number of trees. In addition, we chose two for the number of $n_{\mathrm{r}}$ as well as the Gini Index for the measurement of the best split selection. We parameterized and ran all RF experiments using the EnMAPBox software (van der Linden et al., 2015). All the experiments were performed using the bottom reflectance composites, $R_{\mathrm{b}}$ and 400 training and validation data for all four classes: (a) C. nodosa seagrass, (b) P. oceanica seagrass, (c) Rocky algae, and (d) Sand. The training and validation data were split equally into 50 data 


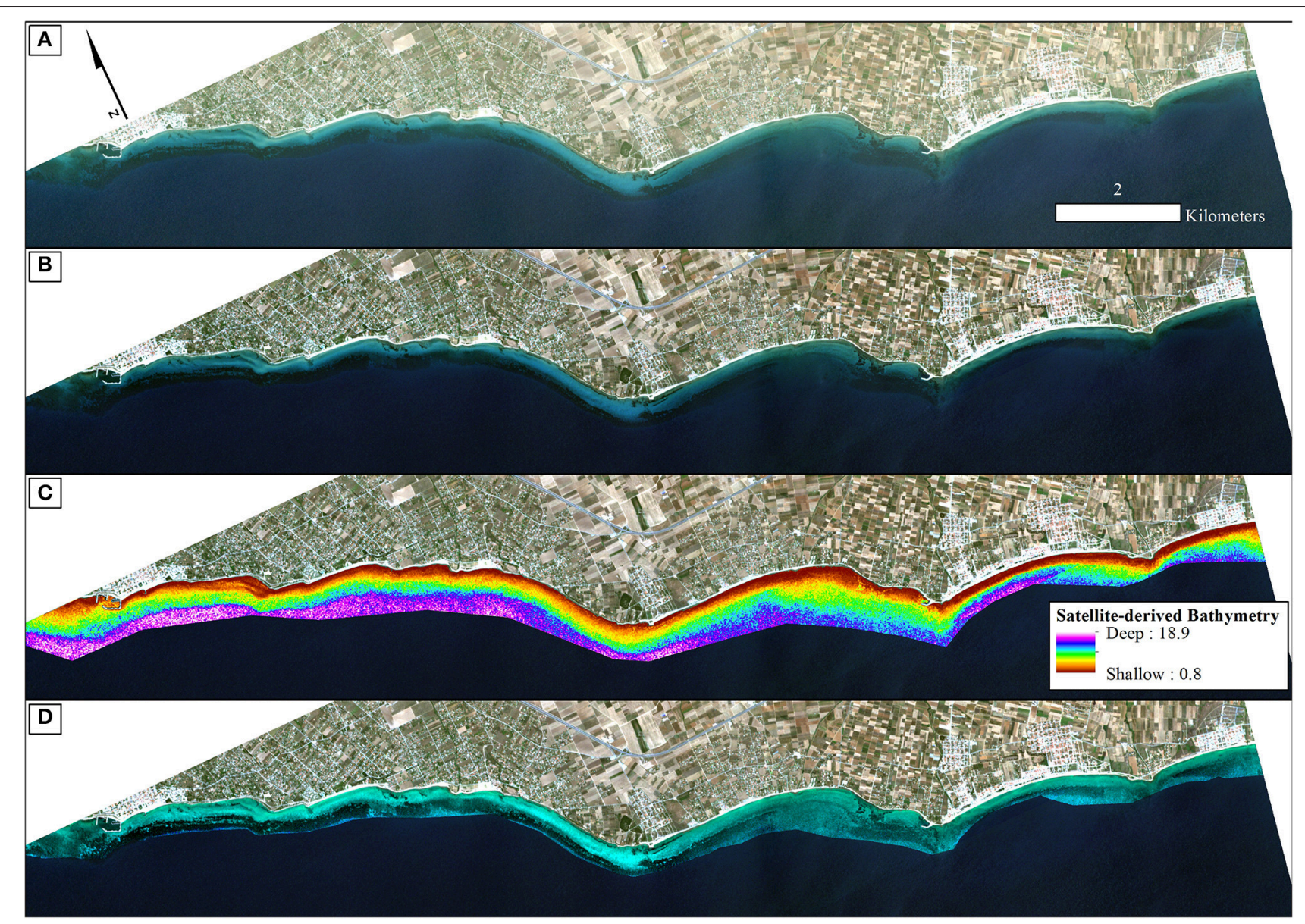

FIGURE 4 | Methodological steps from atmospheric to water column correction in order of successive processing. All four panels are true color RapidEye image composites (22/06/2016; RE16 in text) projected in UTM (zone 34) system/WGS84. (A) Non-atmospherically corrected composite. (B) Atmospherically-corrected composite using the FLAASH module. (C) Satellite-derived Bathymetry map of the survey site draped over the atmospherically-corrected composite of (B) using the site-specific polynomial algorithm of Equation (2) as shown on Figure 3. We applied a $5 \times 5$ low-pass filter on the initial ratio-derived bathymetry (not shown here) to reduce potential noise which would be transferred to the water-column corrected product. (D) Water-column corrected composite following application of the water column correction algorithm of Maritorena et al. (1994) draped over the atmospherically-corrected composite of (B) and masked using the optically deep limit of $16.5 \mathrm{~m}$ to enhance bottom features and potentially increase classification accuracies.

points per class for both training and subsequent validation through accuracy assessment.

\section{Accuracy Assessment}

We used the error matrices (Table 2) to validate the results of the Random Forest classifications. As discussed in Random Forest Classification section, 50 data points per class were used to validate the RF classifier. The error matrix contains a square array of rows and columns where each of them represents one habitat class in the classification. Each cell in this matrix is the number of classified training samples, while the rows comprise classified training data and the columns are validation data for the assessment of the classified data. The error matrix outputs the overall, producer, and user accuracy (Congalton, 1991). The overall accuracy is the ratio of the number of correctly classified validation samples to the total number of validation data (200 in our study). On one hand, the producer accuracy expresses the number of correctly classified validation data in one class divided by the total number of validation data in the same class (50 in our study). On the other hand, the user accuracy corresponds to the number of correctly classified validation in one class divided by the total number of validation data that were classified in the same class. Although the producer accuracy is a solid statistical value for the creator of the habitat map (the remote sensing scientist as the case in point), the user accuracy is more vital from a management point of view as it reports the quantitative probability for the tangible presence of the habitat in the studied region i.e., $P$. oceanica and $C$. nodosa seagrass meadows.

\section{Change Detection}

The ultimate aim of this study is to study the interannual change of two Mediterranean seagrasses, P. oceanica, and C. nodosa, exploiting the high spatial resolution of the RapidEye satellite constellation and the theoretical superiority of the machine 
learning classifier of Random Forests. Here, the interannual seagrass change detection (2011, 2012, 2015, and 2016) is conducted on an area change basis following the machine learning classification of water column corrected RapidEye composites. We report the area change throughout the 5-year time series in hectares in addition to the per-pixel gain, no change and loss between 2011 and 2016. A standard linear regression and associated slope coefficient are implemented to show approximate trends in area over time as well.

\section{RESULTS}

\section{Pre-classification Steps}

All pre-classification steps are displayed schematically in Figure 2 and visually in Figure 4. It is visually apparent that both the atmospheric and water column correction in Figures 4B,D, respectively, enhance bottom features following the increase of the seabed spectral variability from Figure 4A (initial top-of-theatmosphere reflectance composite).

After converting the atmospherically-corrected at-water surface reflectances, $R$ to $R$ rs (1), we developed a site-specific polynomial algorithm (2) using the log-transformed ratio of the blue to green RapidEye bands of the RE16 image (3) to map bathymetry, $Z$, in our site (Figure 4C). The depth of the eastern coast of the Thermaikos Gulf spanned the depth range between 0.8 and $18.9 \mathrm{~m}$ with a mean depth of $7.7 \mathrm{~m}$ and a mean slope of $5.4^{\circ}$. The validation of the Satellite-derived Bathymetry was conducted using 14 in situ depth points and revealed an r-squared value of 0.86 with a root mean square error (RMSE) of $2.6 \mathrm{~m}$ (Figure 5). It is worth noting that from the 32 points used in the bathymetry estimation, 15 were measured above $P$. oceanica beds, 3 over $C$. nodosa beds, 11 over sandy seabed, and 3 over rocky seabed with photophilous algae. On the other hand, from the 14 points used in the bathymetry validation, 8 were over $P$. oceanica beds and 6 over sandy seabed.

Employing Equation (4), we performed water column correction for every pixel in all RE images. Equation (4) takes the at-water surface reflectance, $R$, the per-pixel Satellite-derived bathymetry, $Z$, the reflectance of an optically deep column, $R_{\infty}$, and, finally, the diffuse attenuation coefficient, $K_{\mathrm{d}}$, as inputs and outputs bottom reflectance, $R_{\mathrm{b}}$. The reflectances of an optically deep column were determined based on 25,599 pixels within the deep water polygon of Figure $1 ; R_{\infty}(475)=0.033, R_{\infty}$ $(555)=0.024$, and $R_{\infty}(658)=0.017$. As mentioned in section Water Column Correction, $K_{\mathrm{d}}$ values were selected for the whole time-series from Figure 11 in Traganos and Reinartz (2017); $K_{\mathrm{d}}$ $(475)=0.067, K_{\mathrm{d}}(555)=0.078$, and $K_{\mathrm{d}}(658)=0.134\left(\right.$ in $^{-1}$ as they are calculated based on the unitless $R$ and depth).

\section{Random Forest Classification}

We employed the Random Forest machine learning classifier on all bottom reflectance images which comprised the studied time series (Figure 4D). The results of the random forest classifications are presented in Figure 6. The accuracy assessment of the classification results for all images and habitats is presented in Table 2 with the form of four error matrices, one for each image from RE11 to RE16. All experiments were run using 100 trees. The two Mediterranean seagrasses under study here, $P$. oceanica and C. nodosa, showed a mean producer accuracy of 89 and 50\%, respectively, with a mean user accuracy of 91.6 and

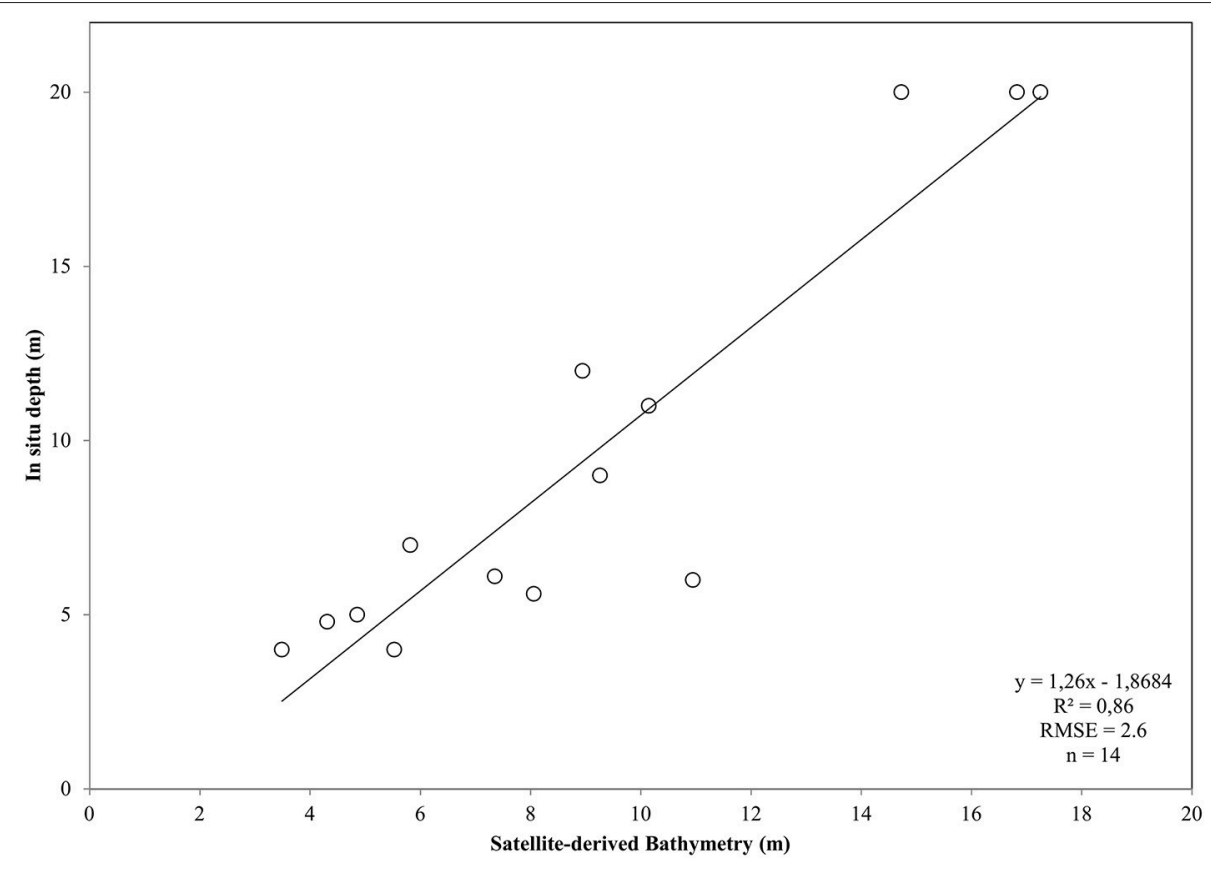

FIGURE 5 | Plot of Satellite-derived Bathymetry (SDB) vs. in situ measured depth for the validation of the bathymetry map of the Thermaikos Gulf (Figure 4C). SDB was derived from Equation (2). Regressed SDB have been previously smoothed with a $5 \times 5$ low pass filter to reduce unwanted noise. 


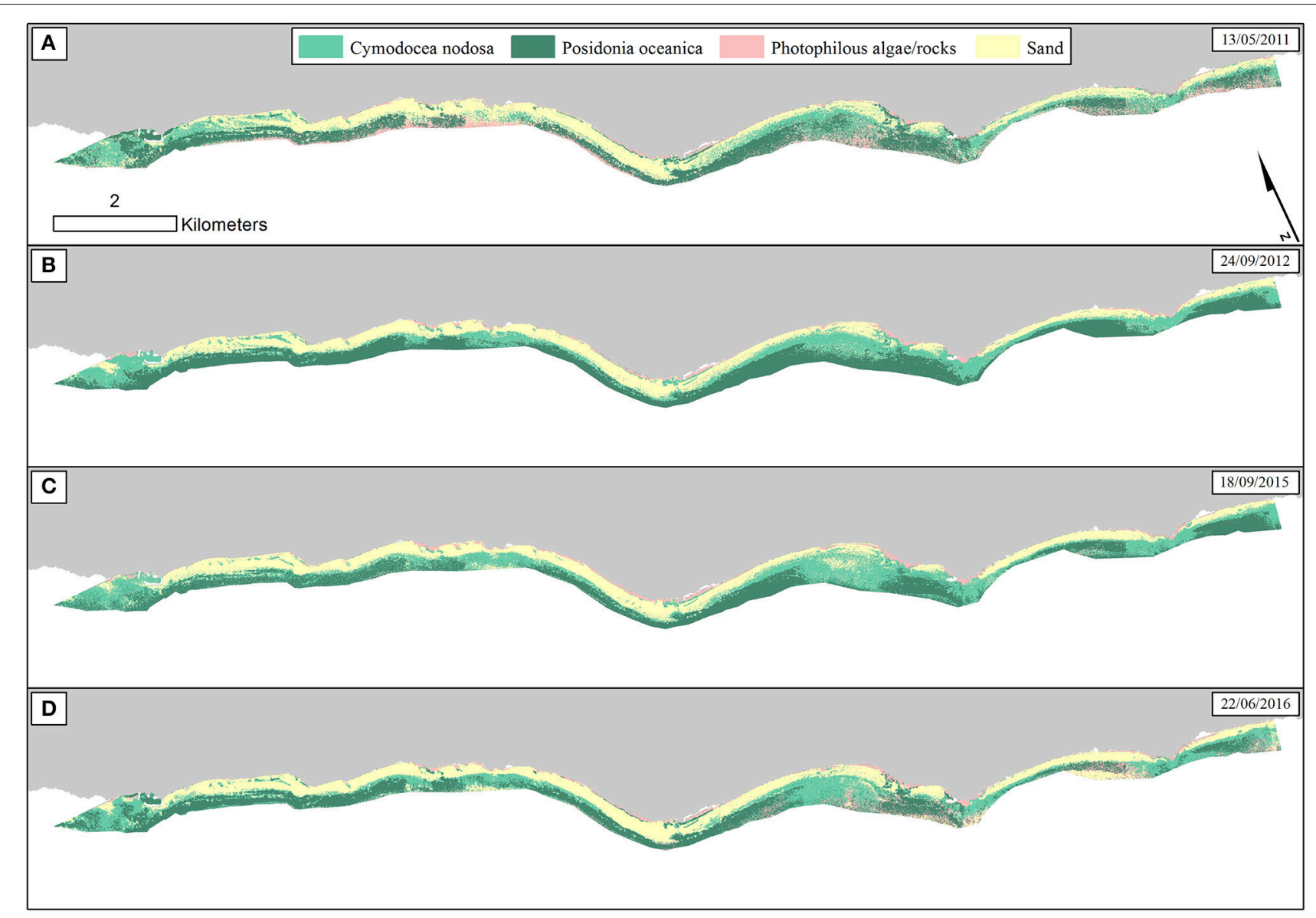

FIGURE 6 | Classified water-column-corrected RapidEye composites from the 4 years using Random Forest machine learning classifier (100 trees). The frames on the upper right of each panel indicate the date of each RapidEye image. (A) RE11-Overall accuracy: 73.5\%. (B) RE12-Overall accuracy: 81\%. (C) RE15-Overall accuracy: 78.5\%. (D) RE16-Overall accuracy: 82\%.

63.1\%, correspondingly. From the whole time-series, P. oceanica seagrass was more accurately classified in RE16 (Figure 6D; 98\% producer accuracy) and RE11 (Figure 6A; 92\% producer accuracy), but less accurately identified in the same images according to the user accuracy of $84.5 \%$ of the former and $86.8 \%$ of the latter. The best user accuracies concerning $P$. oceanica were produced for the RE12 (Figure 6B; 100\%) and the RE15 (Figure 6C; 95\%).

As regards to $C$. nodosa species, RF correctly classified it to $62 \%$ and $60 \%$ producer accuracies in RE12 (Figure 6B) and RE15 (Figure 6C), while the former exhibited the second best user accuracy of $86.1 \%$ following the $92 \%$ of RE16 (Figure 6D). Generally, RE12 featured the second best overall accuracy (81\%), marginally behind RE16 (82\%), but possessed the best mean producer and user accuracies of the two seagrass habitats (76 and $93 \%$, correspondingly). In the contrary, RE11 revealed the worst results with the worst overall accuracy of $73.5 \%$, worst mean producer accuracy (62\%), worst mean user accuracy (81.5\%). Generally, the error matrices indicate that errors in both producer and user accuracies in all four images are mainly attributed to confusion between the two seagrasses and less with sandy or rocky seabed.
Based on the classified water column corrected RE16 composite, $P$. oceanica seagrass meadows covered an area of 264 ha in depths between 0.8 and $17.9 \mathrm{~m}$, with an average depth presence of $8 \mathrm{~m}$. On the other hand, C. nodosa beds covered 242 ha and were spread between depths of 0.8 and $16.1 \mathrm{~m}$, with a mean depth presence of $5.8 \mathrm{~m}$.

\section{Change Detection}

We report the interannual change detection of $P$. oceanica and C. nodosa seagrasses here as change of their extent (Figures 7, 8) following random forest classification of all four RE images (Figure 6). Figure 7 shows the areas of both seagrasses and total seagrass area in each of the four studied years in addition to indicating change trends at species and total level (black lines). We observe that $P$. oceanica area declined by $4.1 \%$ (from 275 to $264 \mathrm{ha}$ ) between 2011 and 2016, while its declining trend was $11.2 \mathrm{ha} / \mathrm{yr}$. On the contrary, C. nodosa area increased by $17.7 \%$ (from 199 to $242 \mathrm{ha}$ ), while its increasing trend was $18 \mathrm{ha} / \mathrm{yr}$. Overall, therefore, the area of seagrasses in the Thermaikos Gulf increased by 6.8\% (474 to 506 ha) between 2011 and 2016, with an increasing trend of $6.8 \mathrm{ha} / \mathrm{yr}$. The highest decrease of P. oceanica seagrass was displayed between 2012 


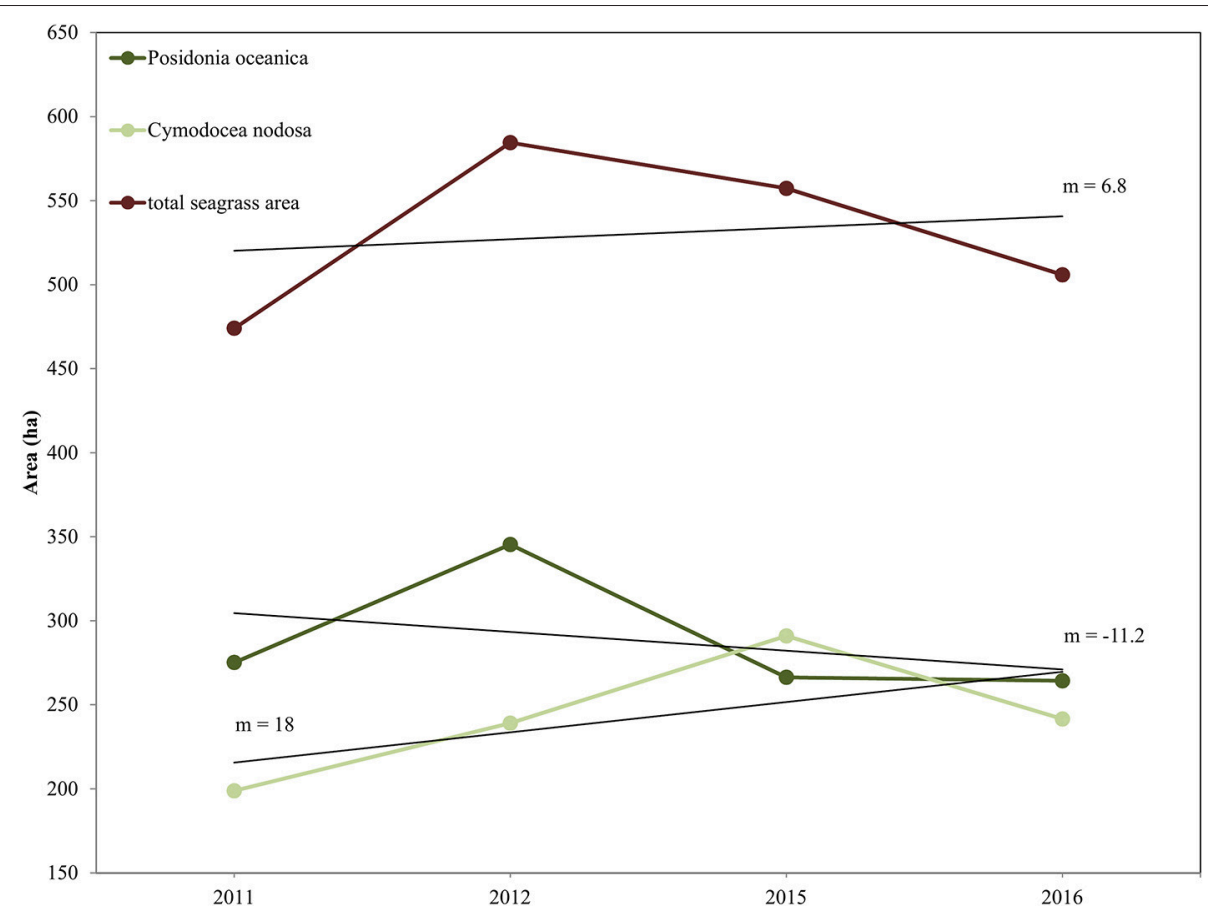

FIGURE 7 | Interranual change detection of seagrasses in the Thermaikos Survey site between 2011 and 2016 using RapidEye satellite images. The trajectory plot displays change of area (in hectares; $y$-axis) over the years ( $\mathrm{x}$-axis) of Posidonia oceanica and Cymodocea nodosa species, and of total seagrass area. Linear regression black lines $(\mathrm{m}=$ slope) show approximate trend in area between 2011 and 2016. Posidonia oceanica seagrass is decreasing at 11.2 ha/yr, Cymodocea nodosa seagrass is increasing at $18 \mathrm{ha} / \mathrm{yr}$, while total seagrass area is expanding at $6.8 \mathrm{ha} / \mathrm{yr}$.

and $2015(-29.7 \%)$, while the highest decrease of C. nodosa seagrass was shown between 2015 and 2016 (-20.5\%), the same period where we observe the greatest decrease of total seagrass area $(-10.2 \%)$.

Figure 8 reveals the change of both studied Mediterranean seagrasses on a gain, no change and loss basis between 2011 and 2016. The greatest losses of $P$. oceanica meadows are depicted on the shallow northwesternmost part and the southeastern part of the center of our survey site (Figure 8A). On the other hand, while C. nodosa exhibit gains throughout the extent of the Thermaikos Gulf, its highest regression is also shown in the shallower seabed of the northwesternmost part. The importance of Figure 8 lies on its capacity to show possible losses of $P$. oceanica seagrass area attributed to gains of $C$. nodosa area. This is indeed the observation in the aforementioned area of the highest regression of $P$. oceanica species (center of our survey site; Figure 8) in addition to the southeasternmost extent of the Thermaikos Gulf site.

\section{DISCUSSION}

\section{Change Detection}

The main objective of this study was to evaluate whether the application of machine learning algorithms, namely Random Forests, on a time-series of high resolution satellite images, namely RapidEye, was effective for mapping the interranual change detection of two Mediterranean seagrasses, $P$. oceanica and C. nodosa, in 888 submerged hectares of the Thermaikos
Gulf, NW Aegean Sea, Greece between 2011 and 2016 (total of four images). As attested by Figure 7, our main findings reveal that the distribution of $P$. oceanica seagrass meadows have declined by $4.1 \%$ with a decreasing trend of $11.2 \mathrm{ha} / \mathrm{yr}$, while C. nodosa beds have increased by $17.7 \%$ with a gain trend of $18 \mathrm{ha} / \mathrm{yr}$. Generally, total seagrass area increased by $6.3 \%$ at a $+6.8 \mathrm{ha} / \mathrm{yr}$ trend throughout the 5 years. Approximate trends of seagrass distribution change are indicated by the slope coefficient of a standard linear regression between seagrass area and related years (Figure 7). This method of presenting remotely sensed time series of seagrass was utilized efficiently in $200 \mathrm{~km}^{2}$ of the Eastern Banks, Moreton Bay, Australia (Lyons et al., 2013).

To the best of our knowledge, the studied regression of $4.1 \%$ of $P$. oceanica meadows between 2011 and 2016 is the first report of regression of this particular seagrass species in the Greek seas and one of the first reports in the whole Eastern Mediterranean, a poorly mapped area. It is also in line with the reported trends in the Mediterranean and globally. Telesca et al. (2015) estimated an average regression of $10.1 \%$ for the whole extent of the Mediterranean basin during the past 50 years, which further increased to $33.6 \%$ for areas with existing historical information; Greece lacks this significant information. Marbà et al. (2014) further estimated that between 13 and 38\% of initial $P$. oceanica meadows have been lost since 1960, with a decreasing trend of $1.74 \% / y r$. On assessing 215 studies worldwide, Waycott et al. (2009) has shown that since 1990, seagrass grounds are disappearing at a median rate of $7 \% / y r$, a 7 -fold increase from the median rate of $0.9 \% / y r$ before 1940 . 


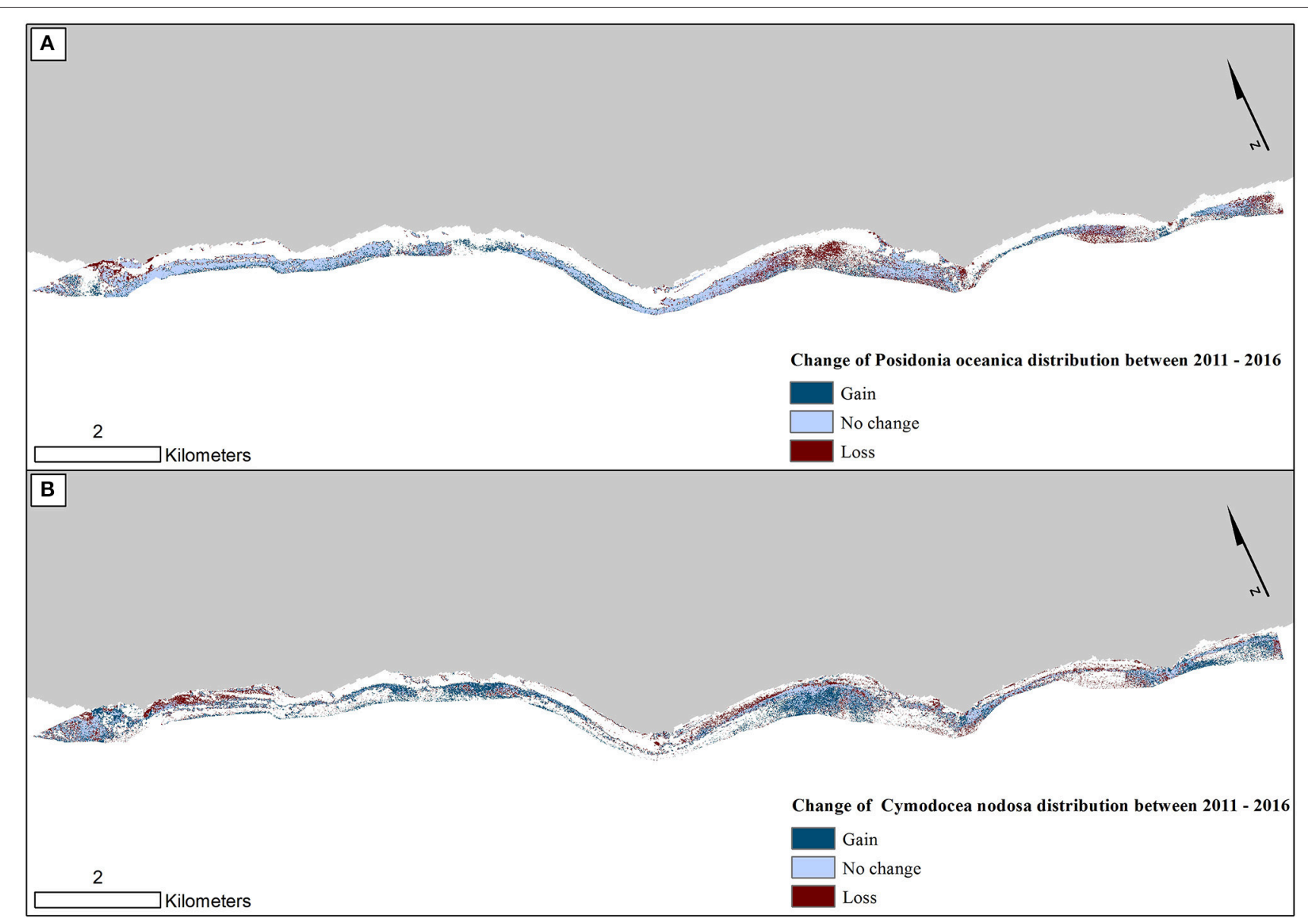

FIGURE 8 | Change in seagrass distribution in the Thermaikos survey site between 2011 and 2016 for (A) Posidonia oceanica and (B) Cymodocea nodosa. Between 2011 and 2016, P. oceanica seagrass meadows have declined by 4.1\%, while C. nodosa seagrasses have increased by $17.7 \%$.

Based on the ecological value of $P$. oceanica, its reported regression of $4.1 \%$ in the Thermaikos Gulf translates into loss of the relevant ecosystem services which it provides in the broader region, including protection from coastal erosion, carbon sequestration, nursery grounds, and nutrient cycling among others. More specifically, the related economic loss to the declining rate of $P$. oceanica of $11.2 \mathrm{ha} / \mathrm{yr}$ is 19.264 million $€ /$ yr (Vassallo et al., 2013). This regression is more alarming due to the slow growth of $P$. oceanica meadows and the existing pressure from climate change. Mortality rates of $P$. oceanica seagrass are expected to increase 3 -fold with an increase of $3^{\circ} \mathrm{C}$ in maximum annual seawater surface temperature ( $\left.\mathrm{SST}_{\max }\right)$ (Marbà and Duarte, 2010). In addition, the temperature of $28^{\circ} \mathrm{C}$ is the critical $\mathrm{SST}_{\max }$, above which $P$. oceanica functional losses accelerate. Study of the specific drivers of the observed $P$. oceanica regression is out of our scope in the present study. Future studies, however, of the temporal dynamics of $\mathrm{SST}_{\max }$ and the extent of $P$. oceanica seagrass meadows could unravel the underlying causes of their regression in the Thermaikos Gulf and elsewhere in the Mediterranean.

On the other hand, C. nodosa seagrass area faced a $17 \%$ increase of its extent, gaining 43 hectares between 2011 and 2016.
We could attribute part of this increase to a combination of two physical factors. First, C. nodosa is a fast-growing seagrass with a reported rate of horizontal growth of up to $2 \mathrm{~m} / \mathrm{yr}$. Second, the decline in terms of $P$. oceanica seagrass allowed the fast recolonization of its regressed beds by the former seagrass, causing the expansion of its area. This substitution of P. oceanica by C. nodosa between 2011 and 2016 is particularly observed in the shallower parts of the northwesternmost, the middle and the southeasternmost regions of the Thermaikos Gulf (Figure 8).

Temporal dynamics of $C$. nodosa distribution have been sparsely studied elsewhere. C. nodosa populations have shown a progression of up to $42 \%$ between 1994 and 2011 in the Western Mediterranean, following a regression of $49 \%$ between 1973 and 1994 (Garrido et al., 2013). Furthermore, C. nodosa seagrass has been found to re-colonize the shallower regressed beds of $P$. oceanica seagrass (Montefalcone et al., 2007). All in all, $C$. nodosa seagrass competes with $P$. oceanica in terms of its expansion, while it is also considered as a significant step in the ecological succession prior to beds of the latter. Further research efforts are needed to increase the body of literature on C. nodosa, in terms of its spatio-temporal dynamics, associated drivers, and 
especially potential links with the ongoing climate change, and its provided ecosystem services.

As regards to the harness of the variety of existing satellite data, numerous studies have assessed seagrass dynamics in a plethora of spatial and temporal scales. In one of the first and most important seagrass change detection assessments, Dekker et al. (2005) exploited four Landsat 5 and 7 images spanning a total of 14 years to map four seagrass species, including ones with great ecologically sensitivity, in Wallis Lake, an estuarine lake in Australia. Pu et al. (2014) also used Landsat 5 data to evaluate seagrass dynamics between 2003 and 2005 in Florida coast. While the two studies monitored change detection of seagrass extent and cover, respectively, Roelfsema et al. (2014) mapped seagrass species, cover and above ground biomass processing a $142-\mathrm{km}^{2}$ time-series of high spatial resolution WorldView-2, IKONOS and Quickbird imagery between 2004 and 2013 with an object-based approach in Moreton Bay, Australia. In another yet exploitation and longest, to the best of our knowledge, of the Landsat archive, Lyons et al. (2012) developed an object-based approach to assess seagrass extent between 1972 and 2010 in Moreton Bay as well. The common denominator of the aforementioned four timeseries studies is that they assessed shallow waters up to $7 \mathrm{~m}$ in contrast to the $16.5-\mathrm{m}$ deep limit in our study. They also all highlight the significance of remote sensing time series of seagrass habitats for seagrass ecology. Roelfsema et al. (2014) argued that the study of the correlation of seagrass-related physicochemical parameters like water quality and temperature with seagrass distribution and composition is vital. Future approaches to this direction could benefit time-series studies and more broadly the management and conservation of seagrasses.

Generally, there is a need for the development of an automated workflow which would exploit the great quantity of remote sensing information and develop time series of seagrass distribution and other management-related parameters in a timeand cost-efficient as well as accurate fashion. This workflow would enable fast assessment of problematic areas (areas of existing or ongoing regression) and raise the need for appropriate management and conservation measures. As mentioned in the Introduction section, however, to achieve accurate time series of seagrass and broadly coastal submerged habitats, one has to select suitable classifier(s) to the subject in study, as classification of these habitats always precede time series analysis.

\section{Classification of Submerged Habitats}

We selected Random Forests to solve the classification problem of discriminating between four habitats in the optically shallow waters of the Thermaikos Gulf, NW Aegean Sea. We run the classification experiments on atmospherically and water-column corrected RapidEye reflectance composites using 100 trees which yielded better quantitative results than other numbers of trees. We also used 50 data for each habitat for both the classification and validation to avoid possible overestimation of any of the classes (Traganos and Reinartz, 2017). It is noteworthy, as Figure 1 shows, that we chose training data only from the southeastern part of our survey site and validation data only from the northwestern part of our survey site. This could have led to biased classified results.
Overall, as reported in the error matrices of Table 2, RF exhibited high accuracies in classifying and identifying both seagrass species and especially $P$. oceanica species, up to $98 \%$ and $100 \%$ producer and user accuracy, respectively. The $5-\mathrm{m}$ pixel-based random forest classification of $P$. oceanica and C. nodosa species displayed slightly worse producer accuracies, but higher user accuracies than similar efforts using Sentinel2A 10-m imagery in the same waters (Traganos and Reinartz, 2017). Particularly for the latter species, its sparse and mixed nature with sandy beds inhibits classification and identification approaches causing the so-called "mixed" pixels. Higher than $5-\mathrm{m}$ resolution approaches employing linear unmixing models and/or object-based classifications could solve this classification issue.

We chose RF to classify and identify Mediterranean seagrasses to achieve more accurate results than simpler, theoretically, algorithms like Maximum Likelihood (Traganos and Reinartz, 2017) which has had a wide application history in the literature of both single- and multi-date studies of seagrass ecosystems (Dekker et al., 2005; Pasqualini et al., 2005; Pu and Bell, 2013; Pu et al., 2014). MLC assumes a normal distribution of classes which is rare in the nature of the examined classes, thus producing inferior results to the more sophisticated machine learning classifiers (Traganos and Reinartz, 2017). RF produced promising results concerning classification of seagrasses recently in two studies (Zhang, 2015; Traganos and Reinartz, 2017). (Zhang et al., 2013) demonstrated the advantage of RF over MLC using hyperspectral imagery. Utilizing 150 trees to run the RF-based experiments, Zhang (2015) achieved better accuracies than the machine learning classifiers of Support Vector Machines (SVMs) and $k$-Nearest Neighbor $(k-\mathrm{NN})$ in identifying patchy seagrass in a $40-\mathrm{km}^{2}$ area in lower Florida Keys, but slightly lower accuracy for continuous seagrass. Traganos and Reinartz (2017) compared RF, SVMs and MLC classifiers in a small section of the surveyed site in the present study. They showed that both RF and SVMs performed evidently better than MLC on classifying P. oceanica and C. nodosa habitats. In the same study, both RF and SVMs displayed lower accuracies on the classification of $C$. nodosa than $P$. oceanica due to the smaller number of field data for the former in addition to its mixed ground with sand.

In summary, machine learning classifiers like RF and SVMs gain more and more interest in coastal habitat remote sensing and, more broadly, in the remote sensing literature (Gislason et al., 2006; Mountrakis et al., 2011). Deep learning techniques concerning submerged habitats are still in their infancy (Call et al., 2003; Calvo et al., 2003) and it is still unknown whether the extra processing power and time to design the experiments are worthy for the potentially better identification that they would offer than machine learning classifiers.

\section{Pre-classification Steps in Detection, Mapping, and Time Series of Submerged Habitats}

The steps which precede the classification and subsequent development and analysis of the time series of submerged habitats include geometric, atmospheric, and water column 
corrections of satellite data in addition to developing satellitederived bathymetry. In the present study, geometric corrections were already done in the Level 3A RapidEye imagery which we processed in the time series. The FLAASH module, implemented for the atmospheric correction, has been already deployed by several studies for studying the change detection of underwater habitats (Lyons et al., 2010, 2011; Pu and Bell, 2013; Roelfsema et al., 2014).

Regarding the water column correction, the analytical model of Maritorena et al. (1994) accurately retrieved bottom reflectances of both $P$. oceanica and $C$. nodosa seagrass species in the RE time series of the present study. In the same area, Traganos and Reinartz (2017) employed successfully the same model to perform water column corrections for the mapping of the two same species. Dierssen et al. (2003) discussed the good agreement of the model's calculated bottom reflectances with in situ ones over dense Thalassia testudinum beds in contrast to overestimated seabed reflectances over beds of the same species of sparse to intermediate density up to depths of $9 \mathrm{~m}$ in Lee Stocking Island, Bahamas. In addition, Pu et al. (2014) conducted water column corrections following the same analytical model to identify three seagrass species (T. testudinum, Syringodium filiforme, and Halodule wrightii) in depths up to $4 \mathrm{~m}$ in Florida, USA. A similar to ours image pre-processing and processing methodological approach to seagrass change detection led to $14 \%$ improved overall accuracies than studies which used analogous data. In another application of Maritorena et al. (1994) water column correction model, Dekker et al. (2005) mapped the change detection of Posidonia australis, Halophila ovalis, Zostera capricorni, and Ruppia megacarpa in the waters of Wallis Lake in Australia, in depths of $<3 \mathrm{~m}$. In antithesis to the field optical measurements of the latter study, we used and developed imagebased estimations of both the diffuse attenuation coefficient and infinitely deep water column reflectance. Future in situ optical measurements are expected to increase accuracies in water column corrections and succeeding classifications and time series analyses, however, these measurements would also raise the cost of the given study.

Regarding the satellite-derived bathymetry, we created a 5-m resolution bathymetry map of the Thermaikos Gulf using RapidEye imagery to aid the RE-based time series of the two Mediterranean seagrass beds. We should note here that we employed the closest imagery to our in situ depth estimations, RE16, to estimate bathymetry for all four images. Traditionally, remote sensing scientists have calculated depth in optically shallow regions by using the band ratio (Lyzenga, 1978). Employing the ratio of blue to green, but in the different central wavelengths of Sentinel-2, 490 and $560 \mathrm{~nm}$, than in the present study, Traganos and Reinartz (2017) developed a bathymetry model for a subsection of the survey site of the present study. They also applied a low pass filter before the estimation of the bathymetry in contrast to the present study where we applied a low pass filter after mapping depth. The lower wavelength of the blue band of RapidEye at $475 \mathrm{~nm}$, however, in comparison to the $490 \mathrm{~m}$ of Sentinel 2 is anticipated to produce more accurate bathymetry estimation due to the higher penetration of the blue band in the water column in this case. Moreover, we chose to convert at-water surface reflectances to the remote sensing reflectances for the development of the bathymetry model as the latter are considered more robust to interactions in the air-water interface and water column constituent composition (Dierssen et al., 2003; Dekker et al., 2011).

The dense canopy and the incidental shading produce the often lower than the adjacent optically deep waters reflectance of P. oceanica seagrass (Dekker et al., 2006). This issue imposes a problem to accurate bathymetry estimations over this type of seabed. Traganos and Reinartz (2017) overcome this problem by modifying the widely utilized bathymetry algorithm of Stumpf et al. (2003) which displayed negative values over P. oceanica beds in relevant experiments. It is worth noting that due to the lack of extensive in situ depth data, we tuned our polynomial algorithm using data, mainly from the southeasternmost part of the Thermaikos Gulf. Nevertheless, as we presented in section Pre-classification Steps, we chose in situ depth data over all four habitats, namely the two seagrasses, sand and rocky seabed with algae, achieving an accuracy of $91 \%$ in the development of the site-specific depth algorithm and a r-squared value of 0.86 with a RMSE of $2.6 \mathrm{~m}$ in the validation of this site-specific bathymetry.

Other studies have used either existing pixel-based depth maps produced with acoustic equipment ( $\mathrm{Pu}$ and Bell, 2013; $\mathrm{Pu}$ et al., 2014), have developed their own satellite-derived bathymetry maps implementing either linear or ratio algorithms (Lyons et al., 2011) or have run simulation experiments of the bathymetry effects using HYDROLIGHT, a robust radiative transfer model. It would be interesting to compare in the future bathymetries derived from all of the above sources to study how accuracies deviate in turn.

\section{CONCLUSIONS}

The present study demonstrates an off-the-shelf methodology to quantitatively assess the spatio-temporal dynamics of seagrasses and other submerged habitats in clear and homogeneous optically shallow waters using Planet's RapidEye time series of four $5-\mathrm{m}$ satellite images. The methodology includes three stages: (a) pre-processing including atmospheric and water column correction of the satellite data along with satellitederived bathymetry, (b) machine learning classification using the Random Forest algorithm, and (c) interannual change detection which is presented here as a change of area and associated trend. We applied these three steps to study the dynamics of two Mediterranean seagrasses, P. oceanica and C. nodosa, in the waters of the Thermaikos Gulf (NW Aegean Sea, Greece) between 2011 and 2016. Total seagrass area has increased by $6.3 \%$ at a rate of $+6.8 \mathrm{ha} / \mathrm{yr}$, while $P$. oceanica seagrass has regressed by $4.1 \%$ at a rate of $-11.2 \mathrm{ha} / \mathrm{yr}$ and C. nodosa seagrass has progressed by $17.7 \%$ at a rate of $+18 \mathrm{ha} / \mathrm{yr}$ throughout the 5 years. In some occasions, C. nodosa has been studied to substitute the regressed beds of $P$. oceanica. The aforementioned trends, especially in terms of the regression of the P. oceanica, are in line with the reported regression of this valuable seagrass elsewhere in the Mediterranean. This study is the first to report spatio-temporal dynamics of both seagrasses in large scales using 
remotely sensed data. The remote sensing of seagrasses lying in optically shallow waters (where the observed surface reflectance contains signal from the bottom in contrast to an optically deep column) faces a plethora of inherent obstacles due to the complex nature of the media above the seagrass beds themselves. Obstacles like water column constituents, sunglint, and skyglint presence, air-water interface interference could impede the detection of seagrasses and require, usually, consideration through relevant algorithms. The presented methodological workflow could act like an alternative ecological assessment showing current trends, revealing regressing seagrasses, and allowing better conservation of these complex but also significant ecosystems. Potential improvements in the given approach could be the existence of in situ optical measurements of several relevant parameters, broader bathymetry field data, advanced radiative transfer simulations, possible comparison of different machine learning algorithms for the improvement of classification and identification of seagrasses and better tuning of those algorithms. Currently, seagrasses are decreasing in alarming rates in a global scale. Linkage of this decreasing trend with the anthropogenic and natural interference through Earth observation of climate change, eutrophication, coastal development as well as temperature, salinity, and hydrodynamic change could develop and refine machine learning models to

\section{REFERENCES}

Barillé, L., Robin, M., Harin, N., Bargain, A., and Launeau, P. (2010). Increase in seagrass distribution at Bourgneuf Bay (France) detected by spatial remote sensing. Aquat. Bot. 92, 185-194. doi: 10.1016/j.aquabot.2009.11.006

Bierwirth, P. N., Lee, T. J., and Burne, R. V. (1993). Shallow sea-floor reflectance and water depth derived by unmixing multispectral imagery. Photogramm. Eng. Remote Sens. 59, 331-338.

Bonacorsi, M., Pergent-Martini, C., Bréand, N., and Pergent, G. (2013). Is Posidonia oceanica regression a general feature in the Mediterranean Sea? Mediterr. Mar. Sci. 14, 193-203. doi: 10.12681/mms.334

Breiman, L. (2001). Random forests. Mach. Learn. 45, 5-32. doi: 10.1023/A:1010933404324

Call, K. A., Hardy, J. T., and Wallin, D. O. (2003). Coral reef habitat discrimination using multivariate spectral analysis and satellite remote sensing. Int. J. Remote Sens. 24, 2627-2639. doi: 10.1080/0143116031000066990

Calvo, S., Ciraolo, G., and la Loggia, G. (2003). Monitoring Posidonia oceanica meadows in a Mediterranean coastal lagoon (Stagnone, Italy) by means of a neural network and (ISODATA) classification methods. Int. J. Remote Sens. 24, 2703-2716. doi: 10.1080/0143116031000066882

Campagne, C. S., Salles, J. M., Boissery, P., and Deter, J. (2015). The seagrass Posidonia oceanica: ecosystem services identification and economic evaluation of goods and benefits. Mar. Pollut. Bull. 97, 391-400. doi: 10.1016/j.marpolbul.2015.05.061

Coll, M., Piroddi, C., Steenbeek, J., Kaschner, K., Ben Rais Lasram, F., Aguzzi, J. et al. (2010). The biodiversity of the Mediterranean Sea: estimates, patterns, and threats. PLoS ONE 5:e11842. doi: 10.1371/journal.pone. 0011842

Congalton, R. G. (1991). A review of assessing the accuracy of classifications of remotely sensed data. Remote Sens. Environ. 37, 35-46. doi: 10.1016/0034-4257(91)90048-B

Costanza, R., d'Arge, R., de Groot, R., Farber, S., Grasso, M., Hannon, B., et al. (1997). The value of the world's ecosystem services and natural capital. Nature 387, 253-260. doi: 10.1038/387253a0

Dekker, A., Brando, V., Anstee, J., Fyfe, S., Malthus, T., and Karpouzli, E. (2006). "Remote sensing of seagrass ecosystems: use of spaceborne and airborne ecologically assess seagrass status worldwide. Harnessing the wealth of Earth observation data that this century offers and state-of-the-art machine learning algorithms, we could better understand the thresholds of different seagrass habitats in different aquatic environments and strengthen their conservation management, allowing a brighter future for these significant ecosystem service suppliers.

\section{AUTHOR CONTRIBUTIONS}

DT conceived and designed the study, collected the in situ data, performed data analysis and interpretation, and drafted the article; PR supervised the whole study, from the conception to the drafting and critical revision.

\section{FUNDING}

DT is supported by a DLR-DAAD Research Fellowship (No. 57186656).

\section{ACKNOWLEDGMENTS}

RapidEye image data were provided by Planet through the project proposal RESA ID 00224.

sensors," in Seagrasses: Biology, Ecology and Conservation, eds A. W. D. Larkum, R. J. Orth, C. M. Duarte (Dordrecht: Springer), 347-359.

Dekker, A. G., Brando, V. E., and Anstee, J. M. (2005). Retrospective seagrass change detection in a shallow coastal tidal Australian lake. Remote Sens. Environ. 97, 415-433. doi: 10.1016/j.rse.2005.02.017

Dekker, A. G., Phinn, S. R., Anstee, J., Bissett, P., Brando, V. E., Casey, B., et al. (2011). Intercomparison of shallow water bathymetry, hydro-optics, and benthos mapping techniques in Australian and Caribbean coastal environments. Limnol. Oceanogr. Methods 9, 396-425. doi: 10.4319/lom.2011.9.396

Dierssen, H. M., Zimmerman, R. C., Leathers, R. A., Downes, T. V., and Davis, C. O. (2003). Ocean color remote sensing of seagrass and bathymetry in the Bahamas Banks by high-resolution airborne imagery. Limnol. Oceanogr. 48, 444-455. doi: 10.4319/lo.2003.48.1_part_2.0444

Fourqurean, J. W., Duarte, C. M., Kennedy, H., Marba, N., Holmer, M., Mateo, M. A., et al. (2012). Seagrass ecosystems as a globally significant carbon stock. Nat. Geosci. 5, 505-509. doi: 10.1038/ngeo1477

Fritz, C., Dörmhöfer, K., Schneider, T., Geist, J., and Oppelt, N. (2017). Mapping submerged aquatic vegetation using RapidEye satellite data: the example of Lake Kummerow (Germany). Water 9:510. doi: 10.3390/w9070510

Garrido, M., Lafabrie, C., Torre, F., Fernandez, C., and Pasqualini, V. (2013). Resilience and stability of Cymodocea nodosa seagrass meadows over the last four decades in a Mediterranean lagoon. Estuar. Coast. Shelf Sci. 130, 89-98. doi: 10.1016/j.ecss.2013.05.035

Giannoulaki, M., Belluscio, A., Colloca, F., Fraschetti, S., Scardi, M., Smith, C., et al. (2013). Mediterranean Sensitive Habitats. DG MARE Specific Contract SI2.600741. Final Report. 557.

Giardino, C., Bresciani, M., Fava, F., Matta, E., Brando, V. E., and Colombo, R. (2015). Mapping submerged habitats and mangroves of Lampi Island Marine National Park (Myanmar) from in situ and satellite observations. Remote Sens. 8:2. doi: $10.3390 /$ rs8010002

Gislason, P. O., Benediktsson, J. A., and Sveinsson, J. R. (2006). Random forests for land cover classification. Pattern Recognit. Lett. 27, 294-300. doi: 10.1016/j.patrec.2005.08.011

Hossain, M. S., Bujang, J. S., Zakaria, M. H., and Hashim, M. (2015). Application of Landsat images to seagrass areal cover change analysis for 
Lawas, Terengganu and Kelantan of Malaysia. Cont. Shelf Res. 110, 124-148. doi: 10.1016/j.csr.2015.10.009

Jordà, G., Marbà, N., and Duarte, C. M. (2012). Mediterranean seagrass vulnerable to regional climate warming. Nat. Clim. Change 2, 821-824. doi: $10.1038 /$ nclimate 1533

Kirk, J. T. O. (1994). Light and Photosynthesis in Aquatic Ecosystems. Cambridge: University Press.

Knudby, A., Newman, C., Shaghude, Y., and Muhando, C. (2010). Simple and effective monitoring of historic changes in nearshore environments using the free archive of Landsat imagery. Int. J. Appl. Earth Obs. Geoinf. 12, 116-122. doi: 10.1016/j.jag.2009.09.002

Leriche, A., Pasqualini, V., Boudouresque, C. F., Bernard, G., Bonhomme, P., Clabaut, P., et al. (2006). Spatial, temporal and structural variations of a Posidonia oceanica seagrass meadow facing human activities. Aquat. Bot. 84, 287-293. doi: 10.1016/j.aquabot.2005.10.001

Lyons, M. B., Phinn, S. R., and Roelfsema, C. M. (2010). Long term monitoring of seagrass distribution in Moreton Bay, Australia, from 1972-2010 using landsat, M. S. S., TM, ETM," in 2010 IEEE, IGARSS (Honolulu), 25-30.

Lyons, M. B., Phinn, S. R., and Roelfsema, C. M. (2012). Long term land cover and seagrass mapping using Landsat and object-based image analysis from 1972 to 2010 in the coastal environment of South East Queensland, Australia. ISPRS J. Photogramm. Remote Sens. 71, 34-46. doi: 10.1016/j.isprsjprs.2012. 05.002

Lyons, M., Phinn, S. R., and Roelfsema, C. M. (2011). Integrating quickbird multispectral satellite and field data. Remote Sens. 3, 42-64. doi: 10.3390/rs3010042

Lyons, M., Roelfsema, C. M., and Phinn, S. R. (2013). Towards understanding temporal and spatial dynamics of seagrass landscapes using time-series remote sensing. Estuar. Coast. Shelf Sci. 120, 42-53. doi: 10.1016/j.ecss.2013.01.015

Lyzenga, D. R. (1978). Passive remote sensing techniques for mapping water depth and bottom features. Appl. Opt. 17, 379-383. doi: 10.1364/AO.17.000379

Marbà, N., Díaz-Almela, E., and Duarte, C. M. (2014). Mediterranean seagrass (Posidonia oceanica) loss between 1842 and 2009. Biol. Conserv. 176, 183-190. doi: 10.1016/j.biocon.2014.05.024

Marbà, N., and Duarte, C. M. (2010). Mediterranean warming triggers seagrass (Posidonia oceanica) shoot mortality. Glob. Change Biol. 16, 2366-2375. doi: 10.1111/j.1365-2486.2009.02130.x

Maritorena, S., Morel, A., and Gentili, B. (1994). Diffuse reflectance of oceanic shallow waters: influence of water depth and bottom albedo. Limnol. Oceanogr. 39, 1689-1703. doi: 10.4319/lo.1994.39.7.1689

Mobley, C. D. (1994). Light and Water: Radiative Transfer in Natural Waters. London: Academic Press.

Montefalcone, M., Albertelli, G., Morri, C., and Bianchi, C. N. (2007). Urban seagrass: status of Posidonia oceanica facing the Genoa city waterfront (Italy) and implications for management. Mar. Pollut. Bull. 54, 206-2013. doi: 10.1016/j.marpolbul.2006.10.005

Mountrakis, G., Im, J., and Ogole, C. (2011). Support vector machines in remote sensing: a review. ISPRS J. Photogramm. Remote Sens. 66, 247-259. doi: 10.1016/j.isprsjprs.2010.11.001

Mtwana Nordlund, L., Koch, E. W., Barbier, E. B., and Creed, J. C. (2016). Seagrass ecosystem services and their variability across genera and geographical regions. PLoS ONE 11:e0163091. doi: 10.1371/journal.pone.0163091

Palandro, D., Andréfouët, S., Dustan, P., and Muller-Karger, F. E. (2003). Change detection in coral reef communities using IKONOS satellite sensor imagery and historic aerial photographs. Int. J. Remote Sens. 24, 873-878. doi: 10.1080/0143116021000009895

Pasqualini, V. C., Pergent-Martini, G., Pergent, M., Agreil, G., Skoufas, L., Sourbes, L., et al. (2005). Use of SPOT-5 for mapping seagrasses: an application to Posidonia oceanica. Remote Sens. Environ. 94, 39-45. doi: 10.1016/j.rse.2004.09.010

Pergent, G., Bazairi, H., Bianchi, C. N., Boudouresque, C. F., Buia, M. C., Clabaut, P., et al. (2012). Mediterranean Seagrass Meadows: Resilience and Contribution to Climate Change Mitigation, A Short Summary / Les herbiers de Magnoliophytes Marines de Méditerranée: Résilience et Contribution à l'atténuation des changements climatiques, Résumé. (Gland; Malaga: IUCN).

Poulos, S. E., Chronis, G. T., Collins, M. B., and Lykousis, V. (2000). Thermaikos Gulf Coastal System, NW Aegean Sea: an overview of water sediment fluxes in relation to air-land-ocean interactions and human activities. J. Mar. Syst. 25, 47-76. doi: 10.1016/S0924-7963(00)00008-7

$\mathrm{Pu}, \mathrm{R}$., and Bell, S. (2013). A protocol for improving mapping and assessing of seagrass abundance along the West Central Coast of Florida using Landsat, T. M., and EO-1 ALI / Hyperion images. ISPRS J. Photogramm. Remote Sens. 83, 116-129. doi: 10.1016/j.isprsjprs.2013.06.008

Pu, R., Bell, S. S., and Meyer, C. A. (2014). Mapping and assessing seagrass bed changes in Central Florida's West Coast using multitemporal Landsat TM imagery. Estuar. Coast. Shelf Sci. 149, 68-79. doi: 10.1016/j.ecss.2014.07.014

Purkis, S., and Roelfsema, C. M. (2015). "Remote sensing of submerged aquatic vegetation and coral reefs," in Remote Sensing of Wetlands: Applications and Advances, ed R. W. Tiner, M. W. Lang, and V. V. Klemas (Boca Raton, FL: CRC Press), 223-242. doi: 10.1201/b18210-15

Roelfsema, C. M., Lyons, M., Kovacs, E. M., Maxwell, P., Saunders, M. I., SamperVillarreal, J., et al. (2014). Multi-temporal mapping of seagrass cover, species and biomass: a semi-automated object based image analysis approach. Remote Sens. Environ. 150, 172-187. doi: 10.1016/j.rse.2014.05.001

Roessler, S., Wolf, P., Schneider, T., and Melzer, A. (2012). "Multispectral remote sensing of invasive aquatic plants using RapidEye," in Earth Observation of Global Changes (EOGC), eds J. M. Krisp, L. Meng, R. Pail, and U. Stilla (Berlin; Heidelberg: Springer), 109-123.

Stumpf, R. P., Holderied, K., and Sinclair, M. (2003). Determination of water depth with high resolution satellite imagery over variable bottom types. Limnol. Oceanogr. 48, 546-556. doi: 10.4319/lo.2003.48.1_part_2.0547

Telesca, L., Belluscio, A., Criscoli, A., Ardizzone, G., Apostolaki, E. T., Fraschetti, S., et al. (2015). Seagrass meadows (Posidonia oceanica) distribution and trajectories of change. Sci Rep. 5:12505. doi: 10.1038/srep 12505

Tomas, F., Turon, X., and Romero, J. (2005). Seasonal and small-scale spatial variability of herbivory pressure on the temperate seagrass Posidonia oceanica. Mar. Ecol. Prog. Ser. 301, 95-107. doi: 10.3354/meps301095

Traganos, D., Cerra, D., and Reinartz, P. (2017). CubeSat-derived detection of seagrasses using Planet imagery following Unmixing-based Denoising: is small the next big? Int. Arch. Photogramm. Remote Sens. Spatial Inf. Sci. 42, 283-287. doi: 10.5194/isprs-archives-XLII-1-W1-283-2017

Traganos, D., and Reinartz, P. (2017). Mapping Mediterranean seagrasses with Sentinel-2 imagery. Mar. Pollut. Bull. doi: 10.1016/j.marpolbul.2017.06.075. [Epub ahead of print].

van der Linden, S., Rabe, A., Held, M., Jakimow, B., Leitão, P. J., Okujeni, A., et al. (2015). The EnMAP-Box - a toolbox and application programming interface for EnMAP data processing. Remote Sens. 7, 11249-11266. doi: 10.3390/rs70911249

Vassallo, P., Paoli, C., Rovere, A., Montefalcone, M., Morri, C., and Bianchi, C. N. (2013). The value of the seagrass Posidonia oceanica: a natural capital assessment. Mar. Pollut. Bull. 75, 157-167. doi: 10.1016/j.marpolbul.2013.07.044

Waycott, M., Duarte, C. M., Carruthers, T. J. B., Orth, R. J., Dennison, W. C., Olyarnik, S., et al. (2009). Accelerating loss of seagrasses across the globe threatens coastal ecosystems. Proc. Natl. Acad. Sci. U.S.A. 106, 12377-12381. doi: 10.1073/pnas.0905620106

Zhang, C. (2015). Applying data fusion techniques for benthic habitat mapping and monitoring in a coral reef ecosystem. ISPRS J. Photogramm. Remote Sens. 104, 213-223. doi: 10.1016/j.isprsjprs.2014.06.005

Zhang, C., Selch, D., Xie, Z., Roberts, C., Cooper, H., and Chen, G. (2013). Object-based benthic habitat mapping in the Florida Keys from hyperpspectral imagery. Estuar. Coast. Shelf Sci. 134, 88-97. doi: 10.1016/j.ecss.2013.09.018

Conflict of Interest Statement: The authors declare that the research was conducted in the absence of any commercial or financial relationships that could be construed as a potential conflict of interest.

Copyright (c) 2018 Traganos and Reinartz. This is an open-access article distributed under the terms of the Creative Commons Attribution License (CC BY). The use, distribution or reproduction in other forums is permitted, provided the original author(s) and the copyright owner are credited and that the original publication in this journal is cited, in accordance with accepted academic practice. No use, distribution or reproduction is permitted which does not comply with these terms. 